\title{
O PROFESSOR E AS NOVAS TECNOLOGIAS NA PERSPECTIVA DA ANÁLISE DO DISCURSO: (DES) ENCONTROS EM SALA DE AULA
}

\author{
Nadia Pereira Gonçalves de Azevedo* \\ Francisco Madeiro Bernardino Júnior \\ Elaine Pereira Daróz ${ }^{* *}$ \\ Universidade Católica de Pernambuco \\ Recife, Pernambuco, Brasil
}

\begin{abstract}
Resumo: A compreensão e a utilização das tecnologias de informação e comunicação tornaram-se uma exigência na sociedade. A Educação não se priva à interpelação e, nesse sentido, tem-se mobilizado. Na rede pública de ensino, a informatização das escolas, a distribuição de notebooks aos professores e de tablets aos alunos são exemplos da interpelação do poder público às novas tecnologias na prática docente. Todavia, uma questão, dentre outras, se apresenta: qual a posição do professor nesse cenário tecnológico? O presente artigo visa a analisar o discurso pedagógico sobre a docência de língua inglesa na era digital. As formulações teóricas da escola de Análise do Discurso de linha francesa, fundada por Michel Pêcheux, constituem o aporte teórico deste trabalho, na compreensão de um sujeito sócio-histórico-ideológico. Partindo da consideração de que o discurso é heterogêneo, buscamos a compreensão da posição-sujeito professor de língua inglesa nesse cenário de constante transformação.
\end{abstract}

Palavras-chave: Professor. Sociedade tecnológica. Análise do Discurso.

1 INTRODUÇÃO

A efervescência tecnológica tem provocado transformações relevantes na sociedade e, assim, suscitado diversas discussões acerca da utilização das tecnologias de informação e comunicação (TIC).

Na sociedade, não raramente, somos impelidos à utilização das novas tecnologias. Quer em atividades cotidianas, como pagar uma conta, quer nas diversas atividades profissionais, nos estudos, as TIC parecem estar cada vez mais presentes. A Educação não está alheia a essa transformação. Na rede pública de ensino, a informatização das escolas, bem como a distribuição de computadores para professores e alunos, é exemplo da interpelação ao uso dos aparatos digitais.

$\mathrm{Na}$ Educação, de acordo com pesquisa realizada em 2009 pelo Instituto Brasileiro de Opinião, Pesquisa e Estatística em abrangência nacional, em um total de 400 escolas

* Programa de Pós-graduação em Ciências da Linguagem. Dra. em Letras e Linguística pela Universidade Federal da Paraíba - UFPB. Email: nadiaazevedo@gmail.com

** Programa de Pós-graduação em Ciências da Linguagem. Dr. em Engenharia Elétrica pela Universidade Federal da Paraíba - UFPB. Email: madeiro@dei.unicap.br

*** Programa de Pós-graduação em Ciências da Linguagem. Mestre em Ciências da Linguagem pela Universidade Católica de Pernambuco - UNICAP. Email: lainedaroz@gmail.com 
detectou-se que $98 \%$ dispõem de computadores, todavia $72 \%$ dos professores admitem não estar preparados para fazer uso do equipamento (IBOPE, 2009). Considera-se que esse é um dado relevante para o país, e o número expressivo de professores que não se sentem aptos à utilização das mídias na prática docente revela o grande desafio da educação brasileira: a inserção de alunos - e professores - no cenário tecnológico.

$\mathrm{Na}$ literatura científica brasileira o foco de investigação dos trabalhos publicados se dá, de modo geral, em torno das tecnologias da informação e comunicação (TIC), em especial seu uso no processo ensino-aprendizagem e aquisição de linguagem. No entanto, considera-se que tais propostas privilegiam uma visão utilitarista dos recursos tecnológicos, bem como seus benefícios na educação, desconsiderando o discurso do professor e sua posição nessa nova era. Nesse sentido, o presente trabalho visa a contribuir para essa temática, buscando a compreensão da posição professor de língua inglesa na era digital, bem como sua compreensão acerca da utilização das TIC na prática docente.

Para tanto, pressupostos teórico-metodológicos da Análise do Discurso de linha francesa constituíram o aporte de uma pesquisa qualitativa, com a participação de quatro professores de língua inglesa que atuam efetivamente em sala de aula, na rede pública de ensino. Foi realizada uma análise a partir de recortes das entrevistas, gravadas individualmente em áudio, tendo em vista um sujeito interpelado ideologicamente, que formula seu dizer a partir de filiações a determinados saberes por processos de incorporação-(des)identificação dos sentidos regularizados na sociedade ao longo dos tempos.

\section{ENSINO DE LÍNGUA INGLESA NA SOCIEDADE TECNOLÓGICA}

A era digital, em especial com o advento da internet, abriu caminhos e trouxe ao homem o acesso a um novo espaço comunicacional. Em meio a uma diversidade linguística e cultural, algumas vezes apontada como forma de inserção na cultura globalizada, a língua inglesa é onipresente de forma mais ou menos explícita, em diversos setores da sociedade.

A fim de atender às necessidades do mundo globalizado, em consonância com a Lei de Diretrizes e Bases da Educação (BRASIL, 1996), a língua inglesa, bem como as demais línguas estrangeiras modernas, antes consideradas complementares, adquire a configuração de uma disciplina tão importante como outra do currículo do ponto de vista da formação do indivíduo no cenário mundial. Integrada à área de Linguagens, Códigos e suas Tecnologias, assume condição de parte indissolúvel do conjunto de conhecimentos essenciais que permitem ao educando aproximar-se de diferentes culturas, propiciando sua inserção no mundo globalizado.

Na mesma direção, os Parâmetros Curriculares Nacionais de Língua Estrangeira (BRASIL, 1998) ressaltam a importância de abandonar um tipo de ensino meramente reprodutivo, para adotar uma modalidade em que haja a aproximação das situações de aprendizagem ao cotidiano do aluno. 
As diferentes estratégias de ensino de língua estrangeira (LE) apontam para uma abordagem comunicativa, trazendo como uma das principais contribuições ao ensino da língua inglesa uma nova dimensão da língua, que deixa de ser vista de forma estática e descontextualizada e passa a ser compreendida a partir de situações sociocomunicativas. De acordo com Littlewood (2002, p. 94), "os métodos comunicativos de ensino contribuem para que o aprendiz desenvolva sua própria personalidade no processo de aprendizagem. Eles também contribuem com o professor que deixa seu papel de professor, para se tornar um ser humano entre seres humanos".

Assim, é requisitada do professor de língua inglesa uma atitude crítico-reflexiva, no sentido de repensar sua prática pedagógica, com vistas a um descentramento de sua posição como transmissor de um conhecimento pré-estabelecido, passando a ser o facilitador e, assim, a melhor contribuir para uma aprendizagem significativa.

Atualmente, há uma variedade de ferramentas à disposição do professor no sentido de promover a autonomia e a busca constante para o aperfeiçoamento do conhecimento, condição impreterível na sociedade em que há uma atualização constante do conhecimento. A utilização das TIC na prática tende a permitir ao aluno a descoberta de novos saberes, levando a uma maior abrangência do objeto de estudo, e ao professor um ambiente propício para uma maior aproximação com aluno num ambiente de troca mútua.

Se utilizadas de forma adequada, as TIC contribuem para o ensino e aprendizado da LE de forma mais dinâmica e prazerosa, uma vez que tendem a favorecer a utilização de estratégias verbais e não verbais necessárias para a efetiva comunicação, fazendo da língua uma forma de acesso às informações e variadas culturas e grupos sociais. As tecnologias abrem para o aluno novas possibilidades de compreensão em relação ao objeto de estudo, na medida em que a língua é apresentada de forma dinâmica, tornando-a mais próxima da realidade do educando. Entretanto, a mera presença de tais dispositivos na sala de aula é garantia de uma inserção de professores e alunos na sociedade da informação?

De acordo com Prensky (2004), os alunos nesse cenário tecnológico são denominados nativos digitais. Para o autor, correspondem aos nativos digitais aqueles que nasceram, e cresceram, em meio à efervescência tecnológica, com tais recursos à sua disposição; uma de suas características é a utilização, em larga escala, dos aparatos digitais. Assim, a acessibilidade a tais dispositivos faz toda a diferença nessa geração.

Considerando que muitos alunos compreendem essa parcela da população, uma vez que cresceram em meio à profusão dos recursos tecnológicos, percebe-se que tais dispositivos podem funcionar como fator motivacional para sua aprendizagem, mas não são, por si mesmos, garantia de uma melhoria na qualidade de ensino, nem tampouco na relação entre professor e aluno. Cabe ressaltar que as novas tecnologias devem ser compreendidas como instrumentos culturais de aprendizagem na prática pedagógica, e surgiram na educação no sentido de aperfeiçoar o processo ensino-aprendizagem e, então, capacitar o educando a viver na era digital, possibilitando-lhe uma visão mais abrangente do mundo. Embora fascinante, o uso das TIC por si mesmo pouco contribuirá para a modernização de uma sociedade se, antes, não houver uma maior compreensão do sujeito sócio-histórico-ideológico, que se realiza no social, na e pela língua(gem). 
No sentido de compreender a posição do professor de língua inglesa como LE na sociedade tecnológica, uma análise do discurso foi realizada sob o aporte teórico da Análise do Discurso de linha francesa, fundada por Michel Pêcheux e desenvolvida por seus representantes no Brasil.

\section{CONSIDERAÇÕES TEÓRICAS}

As reflexões sobre a linguagem sempre estiveram presentes na sociedade, instigando pensamentos no sentido de melhor compreendê-la. Embora com início na Índia, com cunho religioso e, simultaneamente, na Grécia, aproximadamente no ano VI a.C, a partir de estudiosos filósofos, esses estudos sobre a linguagem permaneceram desconhecidos no Ocidente até fins do século XVIII (WEEDWOOD, 2002). Assim como o uso da língua(gem), sua análise com finalidades práticas antecedeu o processo de reflexão da análise científica, privilegiado em tradições de estudos linguísticos individuais, experimentando continuidades e descontinuidades.

Em meio a uma conjuntura dominada pelo Estruturalismo do século XX, vigente ainda nos anos de 1950, e em meio a um período politicamente conturbado na França, nasce a Análise de Discurso (AD) de linha francesa, fundada por Michel Pêcheux, com o objetivo de promover diferentes práticas de leitura com vistas ao questionamento da transparência da língua e da obviedade do discurso (PIOVEZANI; SARGENTINI, 2011). Para tal, aciona alguns conceitos da psicanálise, diretamente ligada a uma noção de sujeito em que estão inscritos os domínios da ideologia e do inconsciente, compreendidos como elementos constitutivos de todo discurso e, assim, do sujeito.

Ao estabelecer o quadro epistemológico da $\mathrm{AD}$, Pêcheux não ficou alheio à concepção lacaniana de um sujeito clivado, banhado de linguagem. De acordo com Lacan (1999, p. 235), "o efeito de linguagem é a causa introduzida no sujeito. Por esse efeito, ele não é causa de si, mas traz consigo o verme da causa que o cinde". Na consideração desse sujeito efeito de linguagem, o sujeito é considerado na sua relação entre língua e história, na medida em que é afetado por discursos que circulam na sociedade. Nessa perspectiva, Authier-Revuz (1982, p. 136) salienta que "o sujeito não é uma entidade homogênea, exterior à linguagem, que lhe serviria para 'traduzir' em palavras um sentido do qual ele seria fonte consciente". Em contrapartida a um sujeito cognoscente e dono de um sentido único da língua, o sujeito não possui total controle sobre o que diz, nem tampouco dos sentidos que circulam no seu discurso, uma vez que é afetado pelo inconsciente, e atravessado pela história, na formulação do seu discurso.

Corroborando essa visão, e em contrapartida a uma univocidade discursiva, Orlandi (2003, p. 32) afirma que "o dizer não é propriedade particular. As palavras não são nossas. Elas significam pela história e pela língua. O que é dito em outro lugar também significa nas 'nossas' palavras.” O sujeito diz, mas não tem acesso ou controle sobre o modo pelo qual os sentidos se constituem nele. Na compreensão de um sujeito histórico-social, o sujeito enuncia a partir de uma anterioridade, um lugar delimitado na história, que constitui o nosso dizer. Dessa forma, o discurso, assim como o sujeito, é constitutivamente heterogêneo. 
Ao formular a sua teoria do discurso, Pêcheux toma em consideração um sujeito interpelado pela ideologia e, por conseguinte, a noção de um sujeito ideológico. Para o autor (PÊCHEUX, 2010, p. 214), influenciado por Althusser (1987), “a Ideologia interpela os indivíduos em sujeitos", sendo a responsável por produzir nele o efeito de evidência, em função de um esquecimento constitutivo que o atravessa, para que produza o seu dizer. Assim, a instância ideológica - "sempre-lá" - se materializa na linguagem e faz parte do seu funcionamento, constituindo-se em condição necessária para ser sujeito. Em contraposição a uma transparência e neutralidade da língua, a relação entre língua e sujeito jamais é inocente, na medida em que todos os discursos são ideológicos e lidam com possibilidades inscritas ao longo da história. De acordo com Pêcheux (2010, p. 254), "os indivíduos são interpelados em sujeitos-falantes (em sujeitos de seu discurso) pelas formações discursivas que representam "na linguagem" as formações ideológicas que lhes são correspondentes". A ideologia não é abstrata, nem tampouco neutra, compreendida como elemento constitutivo do discurso, e do sujeito, opera nestes os efeitos de evidência, a partir de um processo de dissimulação/incorporação.

Segundo Pêcheux (2010), ao enunciar, todo sujeito fala a partir de uma formação discursiva (FD) em que está implícita uma formação ideológica a que ele se filia. Concebida como o ponto de articulação entre língua e discurso, é a responsável por regular o que pode e deve, ou não, ser dito, marcando uma posição de sujeito e conferindo-lhe uma identidade enunciativa. Sendo assim, a FD ocupa papel fundamental na $\mathrm{AD}$, compreendida como o lugar onde se constituem sujeito e sentido.

Na concepção pêcheutiana, cada FD suporta uma ou várias formações ideológicas com as quais o sujeito se identifica. De acordo com Pêcheux (2000, p. 11), "uma ideologia não é idêntica a si mesma, ela não existe senão pela forma de divisão, na luta de contrários". Heterogênea desde a sua constituição, a FD está intrinsecamente relacionada aos processos sócio-históricos que atravessam o dizer e, numa relação de aproximação/oposição, podem ser estabelecidas tanto relações de conflito quanto de aliança.

Corroborando essa visão, Indursky (2008) afirma que, uma vez interpelado ideologicamente, o sujeito identifica-se à FD a que está submisso, e que o constitui como sujeito - a saber, a forma-sujeito, compreendida como sujeito universal - e, assim, reproduz os sentidos decorrentes daquele saber, regularizados na sociedade sob a forma de um "já-dito". Todavia, o sujeito não apenas reproduz os sentidos. De acordo com a autora, os discursos são atualizados, na medida em que, a partir de uma teia sócio-histórica-ideológica, o sujeito pode contraidentificar-se com algum sentido regularizado inerente à $\mathrm{FD}$ que o constitui como sujeito. A contraidentificação do sujeito com a FD que o constitui se dá, assim, na medida em que o sujeito confronta determinados saberes inerentes à FD que o constitui. Por outro lado, o sujeito pode, ainda, desidentificar-se de algum saber, e identificar-se com outro, outra FD. Nesse sentido, a desidentificação se marca pela negação àqueles saberes intrínsecos à sua forma-sujeito e se identifica com saberes outros, inerentes a outra forma-sujeito. 
Para uma melhor compreensão do leitor acerca da posição do profissional de línguas nesse cenário tecnológico, cabe ressaltar breves considerações a respeito do perfil dos sujeitos envolvidos na pesquisa. Os participantes são do sexo feminino e compreendem a faixa etária entre 39 e 45 anos. O tempo de formação (graduação) varia de 15 a 22 anos, dentre os quais de 2 a 10 anos exercidos na rede pública de ensino. Todos possuem especialização em Linguística Aplicada. Ao ingressarem no quadro efetivo da escola regular na prefeitura de Recife, os professores receberam notebooks e curso de formação tecnológica, o qual se restringiu, de um modo geral, ao manuseio do notebook e conhecimento dos aplicativos educacionais nele inseridos.

A análise foi subdividida em dois blocos, a fim de melhor compreensão dos dizeres dos professores, a saber: a importância das TIC na sala de aula, e o discurso da (des)culpa do professor sobre a utilização dessas tecnologias, compreendido por meio das relações de força que se estabelecem entre professor e aluno.

O discurso na AD é compreendido como efeito de sentidos (PÊCHEUX, 1969), que, predeterminados historicamente, são inscritos na formação social, tendo em vista as posições dos sujeitos. Assim, a língua na AD é considerada em seu trabalho simbólico, no jogo dos sentidos regularizados ao longo dos tempos por processos de reprodução/atualização de sentidos inerentes ao discurso.

Nesses termos, a constituição do corpus de análise já é um trabalho analítico, que não obedece a uma ordem cronológica de fatos, mas é considerado, sobretudo, no jogo dos sentidos. As sequências discursivas (SD), constituídas a partir dos recortes das entrevistas com os professores participantes da pesquisa, compõem, dessa forma, a materialidade significante a partir da qual se pode identificar o funcionamento do discurso e, portanto, são apresentadas sem ordem numérica, visto que o foco está nas posições inscritas no discurso. Precisamente, nos recortes apresentados no presente trabalho, os termos SD1, SD2, SD3 e SD4 representam sequências discursivas associadas respectivamente aos sujeitos (professores) 1, 2, 3 e 4 .

\title{
4.1 A IMPORTÂNCIA DAS TIC EM SALA DE AULA
}

De acordo com Pêcheux (2010), a ideologia proporciona ao sujeito os efeitos de evidência a partir de um processo de interpelação-dissimulação. Ancorando-se no jádito e apagando a história, os sentidos vão sendo assimilados no intradiscurso, a partir da apropriação do dizer, e se instalam na sociedade. Para o autor, a interpelação do sujeito em sujeito ideológico se efetua pela identificação do sujeito com a FD que o domina, na qual ele se constitui como sujeito. É possível observar uma identificação do sujeito à interpelação pelo poder público acerca da utilização das TIC em sala de aula nos dizeres dos sujeitos da pesquisa, reconhecida nas expressões "sempre é bom" e "trunfo nas mãos".

\author{
SD2: "é um trunfo nas mãos se souber utilizar..." \\ SD4: “Sempre é bom, né?"
}


A partir de um processo de dissimulação/incorporação dos sentidos regularizados na sociedade acerca do uso das TIC em ambiente escolar, é possível verificar nas formulações a interpelação ideológica, sob a forma de uma identificação do sujeito à FD tecnológica que o constitui, compreendida como sua forma-sujeito. Todavia, a partir das sequências discursivas, observa-se que essa identificação se dá a um nível aparente, na medida em que o sujeito encontra-se assujeitado a esse saber, impelido pelo poder público à utilização de tais recursos na prática docente.

Segundo Courtine (1999), o assujeitamento do sujeito falante, na ordem do discurso, se dá a partir de dois níveis: o nível da enunciação por um sujeito enunciador compreendido como o "eu" dos discursos - em uma situação de enunciação dada; e o nível do enunciado, concebido como uma série de formulações que, a partir de enunciações distintas e dispersas, articula-se em formas linguísticas determinadas sob a forma de citações/repetições, parafraseando, opondo-se entre si e transformando-se. Nesse ponto, o discurso é compreendido como o lugar de confronto entre língua e ideologia. Nos enunciados, é possível perceber esse confronto entre língua e ideologia na interpelação do sujeito acerca do uso das TIC na língua inglesa, a partir das expressões "tem que tá", "tem que levar" no que se refere à sua posição frente às tecnologias.

\section{SD1: "a gente tem que tá acompanhando as mudanças" \\ SD2: " $E$ a gente tem de se fazer, né? Tem de se abrir a isso, tem que deixar as coisas irem acontecendo".}

Não se percebe uma identificação do professor frente ao uso das TIC, mas, antes, uma coerção à sua utilização. Parece haver uma ordem de fazer ou não fazer. Tal pensamento pode ser compreendido, no dizer das participantes, pelo antagonismo dos termos "promessas" e "prática".

SD2: “As promessas são muitas [...] mas na prática nada funcional".

SD1: "isso tudo é muito bacana, mas existem muitos entraves".

É possível notar a contraidentificação do sujeito à FD referente à utilização das TIC, que o constitui a partir das marcas no dizer do sujeito pelo antagonismo dos termos "promessas", "prática" e, ainda, "bacana" e "entraves", realçando a distância entre a teoria e a prática docente. Tal situação proporciona, ao professor, um sentimento de frustração, na medida em que as promessas trazem esperança, porém, na prática, o professor não se identifica com os recursos disponíveis para a utilização das TIC em sala de aula. Observa-se, assim, um desacordo entre o discurso científico, no qual o professor, a priori, reproduz os sentidos regularizados, e sua posição-sujeito na sociedade tecnológica.

Nesse ponto, o sujeito não mais reproduz os sentidos regularizados acerca da utilização das TIC na prática docente, mas opera uma contraidentificação a tais sentidos, confrontando tais saberes acerca dos recursos tecnológicos em sala de aula. Sendo assim, observa-se uma contradição nos dizeres dos professores, que, inicialmente 
identificam-se, embora aparentemente, com a forma-sujeito que os constitui - referente ao uso das TIC na prática docente - passando a confrontar determinados saberes inerentes a ela.

Considerando que a contradição é constitutiva de todo discurso, compreende-se que a relação entre língua e sujeito não é inocente, uma vez que é o lugar onde se materializa a ideologia, e o discurso não é um ponto de concordância, mas se constitui a partir de uma relação de tensão, de embate.

\subsection{DISCURSO DA (DES)CULPA}

Para Grigoletto (2011), o funcionamento ideológico sedimenta determinados sentidos em detrimento de outros, assujeitando os sujeitos do discurso a fazerem determinados usos de palavras, sem que se deem conta dos efeitos de sentido produzidos por esse uso. Uma vez interpelado pelo poder público e, de certa forma, coagido ao uso das TIC na prática docente, o professor se marca no discurso, sem que se dê conta, por meio da busca de uma justificativa para a não utilização de tais recursos. Tal reflexão pode ser compreendida nas afirmações dos professores concernentes à infraestrutura da escola em que trabalham.

\footnotetext{
SD1: "nas escolas em que eu atualmente tou trabalhando, eu não consegui ainda realizar nenhum trabalho de pesquisa com as turmas, porque as escolas não oferecem estrutura".

SD2: "porque a gente tem uma carência muito grande na, em escola pública com relação a esses sistemas".

SD3: "não tem computadores suficientes para os alunos, né?"

SD4: "Na escola que eu trabalho, a gente não tem muito horário para levar os meninos para a sala de informática..."
}

É possível observar que a utilização das TIC na prática docente é vinculada ao laboratório de informática. Nesse ponto, o professor desconsidera o uso dos equipamentos de multimídia, como data-show, que, em geral, é disponível para sala de aula, pelo efeito de naturalização do computador na sociedade tecnológica. Para o professor, o laboratório de informática é a única possibilidade de utilização das TIC, desconsiderando os demais recursos tecnológicos, como celular, TV, aparelho multimídia para utilização em sala de aula, dentre outros. Nesses termos, o sujeito da pesquisa afirma que:

\section{SD2: "A gente vai tentando..." \\ SD4: "A gente faz o que pode".}

Considerando as parcas condições, na concepção do professor, para utilização dos recursos tecnológicos, ele se exime de tal responsabilidade. O professor se desculpa por tal situação, na medida em que declara que "vai tentando", i.e., não está acomodado e, apesar de todas as dificuldades, o professor "faz o que pode" e tenta inserir-se na era digital. 
Todavia, é possível notar que o professor experimenta um sentimento de culpa, na medida em que ele, "responsável pela aprendizagem do aluno", não se sente preparado para usufruir das novas tecnologias, com vistas a favorecer a aprendizagem dos seus alunos - nativos digitais. Observa-se, assim, que, embora o professor se utilize, em maior ou menor grau, dos recursos tecnológicos, ele não se sente à vontade para sua utilização na prática docente.

É possível compreender tal posicionamento a partir das considerações de Prensky (2004) acerca dos imigrantes digitais. Segundo o autor, paralelamente aos nativos digitais, há os denominados imigrantes digitais, ou seja, aqueles que, não tendo crescido em meio à profusão dos recursos tecnológicos, esforçam-se para aprender e usufruir de tais tecnologias. Nesse ponto, no que concerne à posição dos professores participantes da pesquisa, considerados imigrantes digitais, é possível observar que, movido pela interpelação ideológica, o professor se sente coagido e busca atender às exigências tanto do poder público quanto do seu público discente acerca da utilização das TIC em sala de aula.

$\mathrm{O}$ ato de ensinar pressupõe o ato de aprender. E, assim, a posição do professor é correlativa à posição do aluno. No entanto, o que mudou efetivamente no modo de ensinar e aprender no cenário tecnológico? De que forma os estudantes desse novo século compreendem e elaboram as informações?

Segundo Prensky (2004), os nativos digitais preferem, de um modo geral, acessar gráficos a textos e interagir com as tecnologias, gostam de trabalhar em rede e socializar conhecimento, buscam informações aleatórias - em links - ao invés de sequenciais, preferem jogos a trabalhos convencionais, possuem gosto pela criação e são fascinados pelas novas tecnologias. Nesse aspecto, é possível notar um desencontro na educação, no que concerne às posições dos principais agentes do conhecimento, a saber, professor e aluno, resultando numa relação de forças. Tal pensamento pode ser compreendido a partir das sequências discursivas dos professores.

\footnotetext{
SD1: “... há uma interação muito grande do aluno com a, com as novas tecnologias, mas... é, termina, assim, atrapalhando a sala de aula quando eles querem utilizar esses equipamentos em sala..."

SD1: "Então, por essas e outras razões fica difícil e há uma cobrança constante deles e termina como se fosse um pouco a culpa da gente."

SD3: "eles cobram muito a gente"

SD4: "ajuda a melhorar"
}

Pelas expressões "eles querem", "culpa", "eles cobram”, observa-se que os professores se sentem coagidos pelos alunos à utilização de tais tecnologias, na medida em que reivindicam a acessibilidade a tais recursos em sala de aula, revelando um ponto de tensão entre professor e aluno.

De acordo com Pêcheux (2010), as relações de força são inerentes ao discurso e determinadas pelos lugares sociais ocupados pelos sujeitos enunciadores em que, de um modo geral, aquele que ocupa o lugar social de maior prestígio e poder detém maior força no processo discursivo. No mesmo sentido, Azevedo (2000, p. 39) destaca que "a 
relação de forças se refere ao lugar de onde fala o sujeito, ao valor de sua posição no discurso [...] Numa sociedade hierarquizada como a nossa, a fala do lugar do professor, por exemplo, seu dizer vale mais do que o de um aluno". Frente à interpelação do aluno, e do poder público, concernente ao uso das tecnologias, o professor sente sua posição ameaçada perante os alunos, e a tensão já existente entre eles tende a aumentar. Por outro lado, o professor, uma vez submisso ao uso das tecnologias, compreende que tal utilização "ajuda a melhorar" o relacionamento.

Nesse ponto, o professor, julgando-se despreparado para utilizar as tecnologias em sala de aula, sente-se impotente perante a sedução dos alunos às novas tecnologias. Frente a esse dilema, o professor mantém-se distante, apenas observando a identificação do aluno com tais recursos:

\section{SD1: "a gente observa que eles interagem muito bem com as novas tecnologias." \\ SD2: "a gente vê que eles cada dia estão mais conectados" \\ SD4: "a gente observa que eles gostam... eles se sentem motivados [para estudar]"}

$\mathrm{Na}$ fala dos professores, é possível notar que, por um lado, o professor mantém-se como centro do processo ensino-aprendizagem, e, temendo expor suas limitações frente às tecnologias e à perda de autoridade perante os alunos, não se expõe perante seu público. Doutra forma, os alunos - nativos digitais - sentem-se desmotivados com um ensino centralizado no conhecimento do professor, ansiando pela utilização das novas tecnologias em sala de aula.

A partir da análise dos recortes das entrevistas com os professores sobre docência na era digital, bem como suas implicações no ensino-aprendizagem e o relacionamento com o aluno, é possível tecer algumas considerações.

\section{CONSIDERAÇÕES FINAIS}

Este trabalho não se propõe a trazer uma resposta definitiva para as questões aqui levantadas, tendo em vista que toda teoria é constitutivamente incompleta e há, ainda, muito a discutir e considerar sobre tal assunto. Assim, as considerações aqui apontadas constituem um gesto de interpretação, um caminho a seguir dentre tantas possibilidades a partir do trabalho de investigação.

$\mathrm{Na}$ análise apresentada, foi possível observar um desacordo entre o discurso científico concernente ao uso das TIC na prática docente e a posição do professor. Embora o professor reproduza alguns sentidos referentes aos benefícios das tecnologias em sala de aula, manifesta-se pela sua contraidentificação com respeito ao uso de tais recursos na prática docente. Dessa forma, é possível compreender um estranhamento desse profissional quanto à sua posição nesse cenário socioeducacional.

O professor compreende a necessidade de utilização das TIC em sala de aula, porém sente-se incapacitado para fazê-lo. Embora usufrua dos recursos tecnológicos, ainda que a um nível básico, ele não se sente inserido na era digital quando associado à sua prática docente, uma vez que teme por sua autoridade perante os alunos e, assim, 
mantém um distanciamento do aluno, na posição de centro do processo ensinoaprendizagem, na postura de detentor do conhecimento, e não atende à demanda do público discente (nativos digitais).

Deste modo, foi possível perceber uma relação conflituosa na posição do professor concernente à utilização das mídias interativas na sua prática docente, bem como suas implicações no que concerne a uma possível ameaça da suposta estabilidade na sua relação com os alunos. Por conseguinte, o professor experimenta um sentimento de angústia e inquietação, e projeta em seu aluno a imagem do "acusador", aquele que, segundo expresso na fala do professor, culpa-o pela não utilização das TIC em sala de aula. Mediante tal cenário, é realçada a relação de força presente na relação entre professor-aluno.

É inegável que a distribuição de computadores aos professores e alunos e a informatização das escolas representam avanços quanto à inserção do professor na sociedade da informação. A era digital se apresenta como um grande desafio na Educação que, mais do que em qualquer outro tempo, experimenta um choque de gerações com reflexos diretamente no processo ensino-aprendizagem. Mais do que dispor de máquinas e dominar as tecnologias, o que seria difícil, uma vez que se aperfeiçoam de forma acelerada, é preciso um olhar humanista, a fim de valorizar o homem, levando em conta sua pluralidade e a relação com o "outro" - sejam as mídias, sejam os professores e/ou alunos.

Partindo-se da concepção de um sujeito heterogêneo, afetado contraditoriamente pela historicidade e interpelado pela ideologia, e de que a relação do sujeito com a língua se dá por uma tomada de posição, é preciso levar em conta, ainda, o sujeito na história, uma vez que as posições-sujeito não são formadas aleatoriamente, mas construídas socialmente. Assim, em especial na Educação, a era digital provocou uma ressignificação nas formas-sujeito, conforme a análise discursiva realizada neste trabalho pôde mostrar.

\section{REFERÊNCIAS}

ALTHUSSER, L. Aparelhos Ideológicos de Estado. Rio de Janeiro: Edições Graal, 1987.

AUTHIER-REVUZ, J. Hétérogénéité montrée et hétérogénéité constitutive: éléments pour une approche de l'autre dans le discours. Paris: DRLAV, n. 26, 1982.

AZEVEDO, N.P.G. Uma análise discursiva da gagueira: trajetórias de silenciamento e alienação na língua. 2000. 138f. Dissertação (Mestrado em Fonoaudiologia)-Pontifícia Universidade Católica de São Paulo, São Paulo, 2000. Disponível em:

$<$ http://www.pucsp.br/linguagemesubjetividade/PDF/uma_analise_discursiva_da_gagueira_trajetorias_de _silenciamento_e_alienacao_na_lingua.pdf $>$. Acesso em 13 jan. 2013.

BRASIL. IBOPE. Instituto Brasileiro de Opinião Pública e Estatística. 2009. Disponível em: $<$ http://www.fvc.org.br/estudos-e-pesquisas/avulsas/estudos1-7-uso-computadores.shtml?page=3 $>$. Acesso em 15 jan. 2013.

Secretaria de Educação Nacional. Parâmetros Curriculares Nacionais: Ensino médio: linguagens, códigos e suas tecnologias. Brasília: Ministério da Educação /Secretaria da Educação Média e Tecnológica, 1999. 
Ministério da Educação e do Desporto. Secretaria de Educação Fundamental. Parâmetros curriculares nacionais terceiro e quarto ciclos do ensino fundamental: língua estrangeira. Brasília: MEC/SEF, 1998.

LDB. Lei 9394/96. Lei de Diretrizes e Bases da Educação Nacional. Disponível em http// www.planalto.gov.br. Acesso em 30 jan 2013.

COURTINE, J.J. O chapéu de Clémentis. Observações sobre a memória e o esquecimento na enunciação do discurso político. In: INDURSKY, F.; LEANDRO FERREIRA, M.C. (Orgs.). Os múltiplos territórios da Análise do Discurso. Porto Alegre: Sagra Luzzatto, 1999.

FUNDAÇÃO VICTOR CIVITA. 2009. O uso do computador e internet nas escolas públicas de capitais brasileiras. Disponível em: <http://www.fvc.org.br/estudos-e-pesquisas/2009/uso-computador-internetescola-publica-529446.shtml>. Acesso em: 12 set. 2011.

INDURSKY, F. Unicidade, desdobramento, fragmentação: a trajetória da noção de sujeito em Análise do Discurso. In: MITTMANN, S.; CAZARIN, E.; GRIGOLETTO, E. (Orgs.). Práticas discursivas e identitárias - Sujeito e língua. Porto Alegre: UFRGS, 2008.

GRIGOLETTO, E. O discurso nos ambientes virtuais de aprendizagem: entre a interação e a interlocução. In: GRIGOLETTO, E.; DE NARDI, F.S.; SCHONS, C.R. (Orgs.). Discursos em rede: práticas de (re)produção, movimentos de resistência e constituição de subjetividades no ciberespaço. Recife: Ed. Universitária UFPE, 2011.

LACAN, J. O seminário Livro 5: As formações do inconsciente (1957-1958). Rio de Janeiro: Jorge Zahar, 1999.

LITTLEWOOD, W. T. Foreign and second language learning: language acquisition research and its implications for the classroom. Cambridge: Cambridge University Press, 2004.

ORLANDI, E. P. Análise de discurso: princípios e procedimentos. Campinas: Pontes, 2003.

PIOVEZANI, C.; SARGENTINI, V. Legados de Michel Pêcheux e paradoxos da análise do discurso no Brasil. In: PIOVEZANI, C.; SARGENTINI, V. (Orgs.) Legados de Michel Pêcheux: inéditos em análise do discurso. São Paulo: Contexto, 2011.

PÊCHEUX, M. Remontemos de Foucault a Spinoza. Trad. brasileira de Maria do Rosário Gregolin. Campinas: Unicamp/Mimeo, 2000.

Semântica e discurso: uma crítica à afirmação do óbvio. Campinas: Unicamp, 2010.

PRENSKY, M. The emerging online life of the digital native. 2004. Disponível em: $<\mathrm{http}: / / \mathrm{www}$. _of_the_Digital_Native-03.pdf>. Acesso em: 12 jan. 2013.

WEEDWOOD, B. História concisa da linguística. São Paulo: Parábola, 2002.

Recebido em: 12/02/13. Aprovado em: 30/10/13.

Title: Teacher and new technologies in the perspective of Discourse Analysis: (dis)encounters in the classroom

Authors: Nadia Pereira Gonçalves de Azevedo; Francisco Madeiro Bernardino Júnior; Elaine Pereira Daróz

Abstract: The understanding and use of information and communication technologies have become a requirement in today's society. Education hasn't ignored this and, accordingly, has mobilized itself. In educational institutions the computerization of schools, distribution of laptops to teachers and tablets to students are examples of such an understanding by the government of the significance of new technologies in the teaching practice. However, a question among others arises: what is the position of the teacher in that technological scenario? This article analyzes the pedagogical discourse about teaching in the digital age. The theoretical formulations of Discourse Analysis of the French line, founded by Michel Pêcheux, constitute the theoretical basis of this work, which takes into account a sociohistorical-ideological subject. Having in mind that discourse is heterogeneous we intend to understand the subject position of the English teacher in such an ever changing scenario.

Keywords: Teacher. Technological society. Discourse Analysis. 
Título: El profesor y las nuevas tecnologías en la perspectiva de Análisis del Discurso: (des) encuentros en la clase

Autores: Nadia Pereira Gonçalves de Azevedo; Francisco Madeiro Bernardino Júnior; Elaine Pereira Daróz

Resumen: La comprensión y utilización de tecnologías de información y comunicación se han convertido en exigencia en la sociedad. La educación no se priva la interpelación, y así se hay movilizado. En la red pública de enseñanza, la informatización de las escuelas, la distribución de notebooks para profesores y de tablets para alumnos son ejemplos de interpelación del poder público para las nuevas tecnologías en la práctica de enseñanza. Sin embargo, entre otras cuestiones se presenta: ¿cuál la posición del profesor en ese escenario tecnológico? Ese artículo objetiva analizar el discurso pedagógico a cerca de la enseñanza de lengua inglesa en la época digital. Formulaciones teóricas de la escuela de Análisis del Discurso de línea francesa, fundada por Michel Pêcheux, constituyen el aporte teórico de ese trabajo en la comprensión de un sujeto socio-histórico-ideológico. Partiendo de la consideración de que el discurso es heterogéneo, buscamos la comprensión de la posición-sujeto profesor de lengua inglesa en ese escenario de constante transformación.

Palabras-clave: Profesor. Sociedad tecnológica. Análisis del Discurso. 